\title{
EFFECTS OF GRAPHITE ON MECHANICAL PROPERTIES OF STONE MASTIC ASPHALT PAVEMENT
}

\author{
Baha Vural KÖK ${ }^{\mathrm{a}}$, Mehmet YILMAZ ${ }^{\mathrm{a}}$, Yunus ERKUS ${ }^{\mathrm{b}}$ \\ ${ }^{a}$ Department of Civil Engineering, Engineering Faculty, Firat University, 23100, Elazlğ, Turkey \\ ${ }^{b}$ Department of Civil Engineering, Technology Faculty, Firat University, 23100, Elazlğ, Turkey
}

Received 19 Apr 2017; accepted 07 Jul 2017

\begin{abstract}
Hot mix asphalt needs to be developed to resist particular permanent deformations like rutting and thermal cracking due to increased traffic volumes and vehicle loads. Additives such as carbon black, graphite, carbon fibers are used in the mixture or the binder for improving the mechanical features of asphalt. In this article, the effects of graphite used for developing the mechanical properties of asphalt have been investigated in mixtures tests. Therefore, Marshall stability, indirect tensile stiffness modulus and indirect tensile fatigue tests were performed to bituminous mixtures modified with three different proportions of graphite by weight of bitumen. Stone mastic asphalt mixtures which were manufactured with pure and modified bitumen were aged in different time intervals in the oven. In conclusion, it has defined that Marshall stability values have declined. It has been determined that there is no significant difference in the time-dependent deformation behavior of the original and aged samples in pure and different graphite content although the stiffness modulus and load repeat number of the samples increased with the rise of the aging time. These results shown that graphite generally used for improving the thermal properties in literature were also determined to contribute to mechanical properties of mixtures.
\end{abstract}

Keywords: graphite, stone mastic asphalt, aging, mechanical properties, bitumen, pavement.

\section{Introduction}

Large parts of transport in the world are made with highways and heavy traffic increases day by day thereby the roads are structurally damaged. Heavy vehicle traffic and overmuch load repetition, as well as environmental factors, cause major disruptions on the roads. There are various ways of preventing these disruptions. One of these ways is to obtain more powerful mixtures by changing the aggregate gradation (Liu et al. 2012). In practice, the most obvious example of this is stone mastic asphalt (SMA). Using of stone mastic asphalt earns high durability, low permeability, low traffic noise pollution, high strength against reflective cracks and high strength against rutting properties to asphalt layer in the road (Austroads Technical Report 2002). It was also determined that elastic property of SMA could be improved by adding waste polyethylene terephthalate and styrenebutadiene-styrene (Moghaddam et al. 2012; Mokhtari, Nejad 2012). Another way to prevent of these distortions is to modify the bitumen. Due to viscoelastic behavior of bituminous binder, mechanical features of asphalt pavement vary significantly because of daily and seasonal temperature changes. Asphalt concrete temperature can ascend to $70{ }^{\circ} \mathrm{C}$ in summer owing to it's over absorp- tion parameter (Van Bijsterveld et al. 2001). Furthermore, this incident eventually deteriorates the durability of pavement. It will trigger the permanent deformations of pavement with the impact of loads (Tongyan et al. 2012). It was determined that thermal expansion were slightly larger than the thermal contraction (Mamlouk et al. 2005) There are various ways to prevent deteriorations occurred from high temperatures in the pavement. One of them is the use of thermally conductive materials in order to improve the resistance of pavement to the adverse effect of high temperature. Du and Wang (2015) showed that using graphite in asphalt mixture can successfully transmit the temperature to the bottom layers. It was determined that the temperature decreased $6.5^{\circ} \mathrm{C}$ at the $4 \mathrm{~cm}$ depth from the surface which induced $43.5 \%$ decrease in rutting by using graphite as an additive. Liu et al. (2014) determined that using $40 \%$ graphite with $0.3 \%$ carbon fiber induces $78 \%, 15 \%$ and $4 \%$ increase in dynamic modulus, indirect tensile strength and Marshall stability of the bituminous mixtures respectively. Lu et al. (2008) produced conductive asphalt concrete using steel slag as aggregate and graphite in bituminous mixtures. They have concluded that Marshall stability and dynamic

Corresponding author: Baha Vural Kök

E-mail: bvural@firat.edu.tr 
stability values of mixtures declined a bit with the rise of graphite percentage, but these mechanical properties values still compensate the standard requirements. The authors recommended constructing thermal-modified pavement structure in order to improve the rutting and fatigue cracking resistance (Chen et al. 2016).

Another important issue about the deterioration of bituminous mixture is aging processes. Firstly the bitumen used asphalt mixtures are subjected to short-term aging during production and paving processes and then exposed to long-term aging throughout service life. The chemical change due to oxidation results in a harder, more brittle asphalt mixture, which induces low temperature cracking, fatigue cracking or another mode of distress. It was determined that mixing time has an effect on the mechanical properties of SMA during the production. It was also stated that different batching technologies impact an unstable bitumen short-term aging (Bražiūnas et al. 2013). Researchers have been studying on mitigating the adverse effects of aging by using various additives and also investigates new technics to evaluate the aging processes. Warm-mix-asphalt additives which induced a reduction in mixing and compaction temperature was reported to be used successfully for the stone mastic asphalt (Kim et al. 2015). The influence of the additives especially after long-term aging should be observed in order to make a comprehensive evaluation about the service life of hot mixtures. It was determined that aging induces more stiffness for the unmodified mixtures than for polymer or rubber modified mixtures (Radziszewski 2007). Wang et al. (2015) showed that Styrene-butadiene-styrene (SBS) which is a widely used binder additive and significantly contribute to the performance of unaged binder may lose its modifying function after long-time aging. FT paraffin wax was found to be effective in enhancing the resistance to aging (Aghazadeh Dokandari et al. 2014). The improvement effects of crumb rubber on short-term aging properties of asphalt binder are reported by the researchers (Dong, Tan 2011; Reed 2010; Shatnawi 2012). Conversely it was determined that the asphalt binder source rather than the nanoparticle content plays an important role in determining the influence of long-term ageing process (Xiao et al. 2011). In another study, the thermal properties of graphite added binders are examined. It is found that graphite improves the antiaging properties of the bitumen (Pan et al. 2014). Yao et al. (2016) investigated the effects of 1-2\% graphite nanoplatelets on asphalt binder properties. It was determined that aging groups increases in the graphite modified binder which results in an increased resistance to rutting and moisture damage. Graphite nanoplatelets also improve the resistance to cracking.

Although there are some studies about the thermal properties of bituminous mixtures containing graphite, there are limited studies about the effect of graphite on mechanical properties of stone mastic asphalt mixtures. In this study, the effects of the different amount of graphite on the mechanical properties of mixtures were investigated in large-scale.

\section{Materials}

In this article, the aggregate and the filler used to manufacture of the asphalt mixtures are chosen as the limestone. The bitumen (B 50/70) supplied from TÜPRAŞ refinery was utilized for the produce of modified binders. The properties of the bitumen are given in Table 1. Graphite powder passing the No. 200 sieve $(0.075 \mathrm{~mm})$ has a carbon content of $85.7 \%$, an electrical resistivity of $10^{-4} \Omega . \mathrm{m}$ and a density of about $2.15 \mathrm{~g} / \mathrm{cm}^{3}$. Elemental analysis of graphite used in bitumen modification is given in Table 2. SEM image of graphite powder is also shown in Figure 1. In the mixture samples, the limestone's aggregate characteristics were given in Table 3 was used.

\section{Test sample preparation}

Bituminous hot mixture samples were prepared as stone mastic asphalt, which has high resistance to the rutting,

Table 1. The properties of the bitumen

\begin{tabular}{lc}
\hline \multicolumn{1}{c}{ Properties } & Value \\
\hline Penetration $\left(25^{\circ} \mathrm{C}, 100 \mathrm{~g}, 5 \mathrm{~s}, 0.1 \mathrm{~mm}\right)$ & 51.2 \\
Softening point $\left({ }^{\circ} \mathrm{C}\right)$ & 52.2 \\
Penetration indeks & -0.6 \\
Density $\left(\mathrm{g} / \mathrm{cm}^{3}\right)$ & 1.013 \\
Viscosity $\left(\mathrm{cP}, 135^{\circ} \mathrm{C}\right)$ & 600 \\
Viscosity $\left(\mathrm{cP}, 165^{\circ} \mathrm{C}\right)$ & 175 \\
\hline
\end{tabular}

Table 2. The elemental analysis of the graphite

\begin{tabular}{ccccccc}
\hline $\begin{array}{c}\mathrm{C} \\
(\%)\end{array}$ & $\begin{array}{c}\mathrm{N} \\
(\%)\end{array}$ & $\begin{array}{c}\mathrm{H} \\
(\%)\end{array}$ & $\begin{array}{c}\mathrm{S} \\
(\%)\end{array}$ & $\begin{array}{c}\mathrm{O} \\
(\%)\end{array}$ & $\begin{array}{c}\text { Moisture } \\
(\%)\end{array}$ & $\begin{array}{c}\text { Ash } \\
(\%)\end{array}$ \\
\hline 85.7 & - & - & 0.1 & 12.9 & 0.4 & 0.6 \\
\hline
\end{tabular}

Table 3. Physical properties of aggregate

\begin{tabular}{llcccc}
\hline \multicolumn{1}{c}{ Properties } & \multicolumn{1}{c}{ Standard } & Limits & Coarse & Fine & Filler \\
\hline Abrasion loss (\%) (Los Angeles) & ASTM C 131 (2014) & Max 30 & 25 & - & - \\
Frost action (\%) $\left(\mathrm{Na}_{2} \mathrm{SO}_{4}\right)$ & ASTM C 88 (2013) & Max 10 & 4.5 & - & - \\
Flat and elongated particle (\%) & ASTM D 4791 (2010) & Max 10 & 4 & - & - \\
Water absorbtion (\%) & ASTM C127 (2015) & Max 2 & 1.37 & - \\
Specific gravity (Gsb) & ASTM C127 (2015) & & 2.613 & - & - \\
Specific gravity (Gsb) & ASTM C128 (2015) & & - & 2.622 & - \\
Specific gravity (Gsa) & ASTM D854 (2014) & & - & - & 2.711 \\
\hline
\end{tabular}




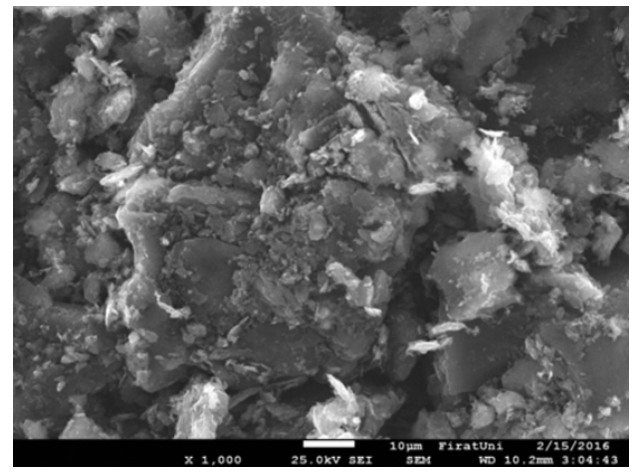

Fig. 1. SEM image of graphite

has a high durability due to the high bitumen content and has recently been widely used in high standard roads. Gradation prepared according to Turkish Highway Technical Specification stone mastic wear layer Type-1 is shown in Table 4 and was designed in accordance with standard Marshall design method. In order to compare the effects of graphite powder on mechanical performance of asphalt mixture, all the mixture samples were prepared with the same gradation and same asphalt content.

Table 4. The gradation of the stone mastic asphalt

\begin{tabular}{l|c|c|c|c|c|c|c|c}
\hline $\begin{array}{l}\text { Sieve size } \\
(\mathrm{mm})\end{array}$ & 19 & 12.5 & 9.5 & 4.75 & 2.0 & 0.425 & 0.180 & 0.075 \\
\hline Passing (\%) & 100 & 95 & 62.5 & 37.5 & 25 & 17 & 13 & 10 \\
\hline
\end{tabular}

Asphalt binder $(500 \pm 5 \mathrm{~g})$ was firstly heated to $165 \pm 5^{\circ} \mathrm{C}$ in the container. Then, graphite was added gingerly within $10 \mathrm{~min}$, while the shear speed was kept at $1000 \mathrm{rpm}$. Hot mix asphalt samples were prepared with the bituminous binders. Graphite was added into pure bitumen in 3 different ratios as $10 \%, 15 \%$ and $20 \%$ by weight of bitumen used in mixtures and they were represented as $0 \%(\mathrm{G} 0), 10 \%(\mathrm{G} 10)$, $15 \%$ (G15) and 20\% (G20), respectively. The stone mastic asphalt mixtures obtained with pure and modified binders were aged for 1,2 and 3 weeks in the oven at $50{ }^{\circ} \mathrm{C}$. In the study totally 4 different mixtures were evaluated with aging. The effects of graphite on mixture's properties were examined by Marshall stability, indirect tensile fatigue and indirect tensile stiffness modulus tests with cylindrical shape specimens prepared $101 \mathrm{~mm}$ diameter and $65 \mathrm{~mm}$ height.

\section{Test methods}

\subsection{Marshall stability test}

Marshall stability test on hot mix asphalt specimen was applied according to TS EN 12697-34 (2004). Stability is described as the maximum strength against deformation. Flow is also the vertical deformation that occurs in time which reaches the maximum load of the sample in the standard. The samples were stored in a water bath at $60 \pm 1{ }^{\circ} \mathrm{C}$ for 40 minutes. The samples were loaded at a speed of $50 \pm 2 \mathrm{~mm} / \mathrm{min}$. In the experiment, the maximum load and deformation occurred at the maximum load were recorded.

\subsection{Indirect tensile stiffness modulus test}

The stiffness modulus which is a measure of the load distribution capability of bituminous pavement is one of the most important performance characteristics of bituminous hot mixtures (Zoorob, Suparma 2000). The indirect tensile stiffness modulus (ITSM) test, a non-destructive and deformation-controlled test, described in BS DD 213:1993 standard and it is carried out by using the UMATTA (Universal Material Testing Apparatus). The test apparatus are shown in Figure 2. The test was carried out at $20{ }^{\circ} \mathrm{C}$. Before the experiment, the samples were kept at the test temperature for at least 3 hours. The values such as sample height, diameter, estimated Poisson ratio (0.35), target horizontal deformation $(6.5 \mu \mathrm{m})$, load application time $(3000 \mathrm{~ms})$ and load rise $(124 \mathrm{~ms})$ times were entered the software. ITSM values $S m(\mathrm{MPa})$ were calculated according to following formula:

$$
S m=F(R+0.27) / L H,
$$

where $F$ is the maximum vertical load $(\mathrm{N})$; $H$ is the average horizontal deformation $(\mu \mathrm{m})$ occurring after 5 load repetition; $L$ is the average sample thickness $(\mathrm{mm})$ and the $R$ is the Poisson ratio (0.35).

\subsection{Indirect tensile fatigue test}

The bituminous materials used on the roads are exposed to a short time load during the passage of each vehicle.
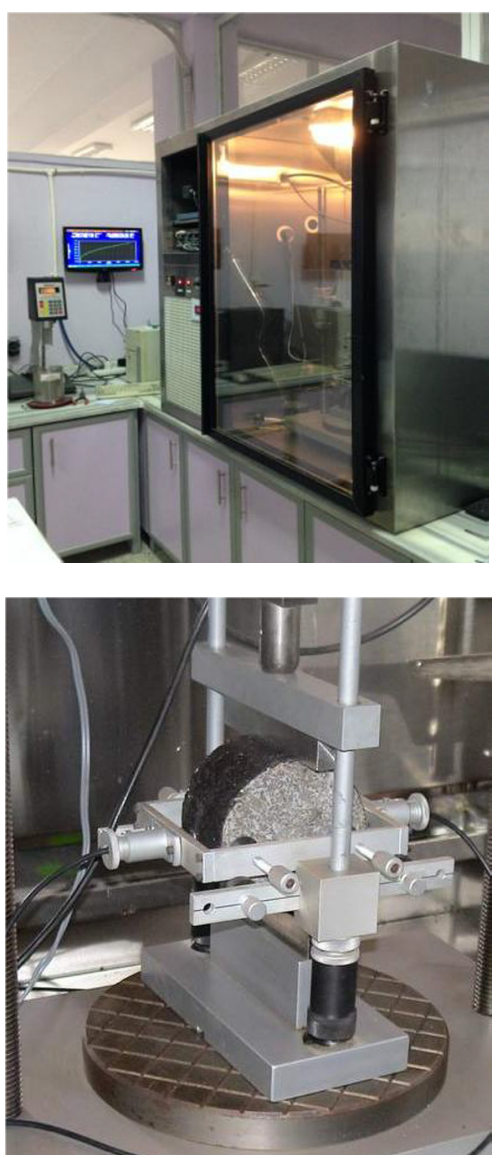

Fig. 2. The indirect tensile stiffness modulus test apparatus 
These loads lead to micro-damage which reduces the rigidity of the material. These micro- damages cause pavement deterioration called fatigue cracks in long-term (Francken 1998). Fatigue cracks commonly occurred at bituminous hot mixtures, are the type of deterioration caused by the load. Fatigue cracks are gradually increasing by following the formation of the crack with repetitive loads. The cylindrical test specimens are applied to repeated pressure loads in the vertical diametric plane. This loading creates tensile stresses relatively uniform in the horizontal diametrical direction and vertical to the applied load direction. The tensile stresses cause to split in the middle at the vertical direction of the specimen. The test apparatus are shown in Figure 3. The test was carried out at stress controlled condition by applying cyclic constant loads of $350 \mathrm{kPa}$ with a 0.1 -s loading followed by a 1.4 -s rest period. The test was carried out at $20^{\circ} \mathrm{C}$. The experiment continued until the specimens completely collapsed.

\section{Results and discussions}

\subsection{Marshall stability test results}

Marshall specimens were prepared by applying 50 blow on both sides due to determine the optimum bitumen ratio of the asphalt mixtures prepared with the pure binder. The bituminous content was selected with $0.5 \%$ increments from $5 \%$ to $7 \%$. The fiber which is used for stabilizing the high amount of binder was used as $0.5 \%$ by weight of the mixture. The volumetric properties such as bulk specific gravity $(\mathrm{Gmb})$, air void (Va), voids in mineral aggregate (VMA), voids filled with asphalt (Vfa) and the stability-flow values of the samples prepared in different bitumen contents were determined. The optimum bituminous content of the pure mixture was determined as $6.5 \%$. The graphite-added samples were prepared in the same bitumen content. The average values of the characteristics of all samples with $6.5 \%$ bitumen content are given in Table 5. It was found that Marshall stability values declined with the increasing of graphite content. This reduction can be thought to be due to the oily properties of graphite. The maximum usage of graphite $(20 \%)$ induces only $6 \%$ reduction in stability. All of the mixtures provide the minimum VMA and air voids requirements which are $16 \%$ and $3-4 \%$ respectively. Stone mastic asphalt mixtures give high flow values compared to dense graded mixtures. An example of a stability-flow relation

Table 5. The average values of the characteristics of the mixtures

\begin{tabular}{l|c|c|c|c|c|l}
\hline $\begin{array}{c}\text { Specimen } \\
\text { Type }\end{array}$ & Gmb & $\begin{array}{c}\text { Va } \\
(\%)\end{array}$ & $\begin{array}{c}\text { VMA } \\
(\%)\end{array}$ & $\begin{array}{c}\text { Vfa } \\
(\%)\end{array}$ & $\begin{array}{c}\text { Stabilitiy } \\
(\mathrm{kgf})\end{array}$ & $\begin{array}{l}\text { Flow } \\
(\mathrm{mm})\end{array}$ \\
\hline G0 & 2.307 & 3.59 & 17.07 & 79.91 & 962.55 & 6.80 \\
G10 & 2.313 & 3.34 & 16.86 & 80.10 & 938.23 & 6.33 \\
G15 & 2.306 & 3.59 & 17.08 & 78.96 & 929.40 & 6.62 \\
G20 & 2.308 & 3.53 & 17.02 & 79.27 & 905.18 & 6.86 \\
\hline
\end{tabular}
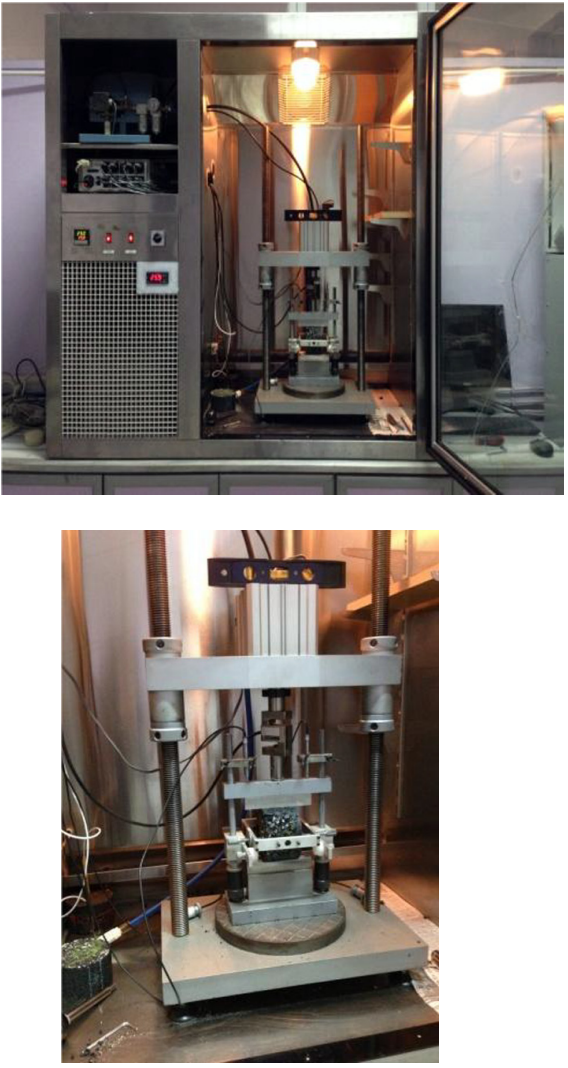

Fig. 3. The indirect tensile fatigue test apparatus

is given in Figure 4 (Kok et al. 2014). As it is seen here that SMA mixtures hold the load in its body longer than that of the dense graded mixtures due to having a coarse gradation. Therefore SMA mixtures do not show a peak stability value, it bears the load longer than the dense graded mixture in the meantime it exhibits high flow values.

\subsection{Indirect tensile stiffness modulus test results}

For this experiment, three samples were prepared for each sample type. Each sample was subjected to loading at three different locations and 9 values were obtained for a sample type. ITSM values were determined by calculating the averages of the seven values outside the largest and the smallest of these values. The test was carried out at $20^{\circ} \mathrm{C}$ with deformation control. The target deformation was set to 6.5 microns.

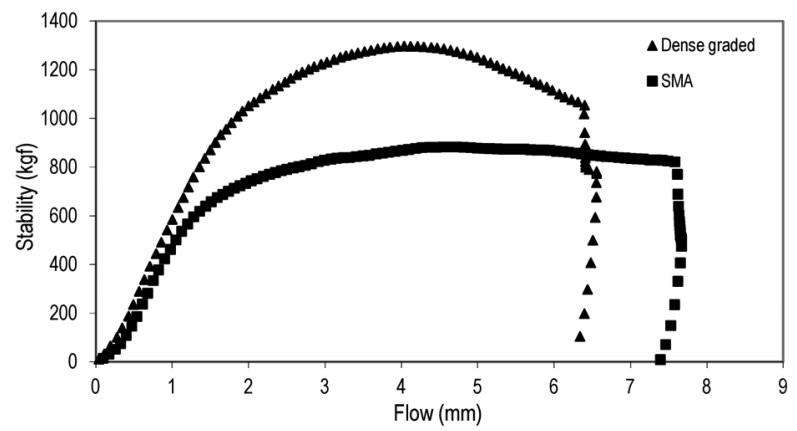

Fig. 4. The stability-flow curves of SMA and dense graded asphalt (Kok et al. 2014) 
At first, the deformation-time characteristics of the specimens were examined. The deformation-time relation of the original and aged samples is given for pure and $20 \%$ graphite added samples in Figure 5. At the representation of the specimen the first number indicate the graphite content and the second one presents the aging time in a week. G20-3 stand for 20\% graphite added samples aged 3 weeks at $50{ }^{\circ} \mathrm{C}$ in the oven. It is seen from the figures that the deformations return since the load is removed after the sample reaches to the maximum target deformation at about 150 milliseconds. It was determined that the deformations at 400th milliseconds are between 2 and 3 microns in all graphite contents. Even at the highest graphite level (20\%), there is no significant difference either positively or negatively in the elasticity properties compared to the pure mixture. The effects of aging time on deformation characteristics do not so important for both pure and graphite added mixtures.

The area under the stress-deformation curves is considered as a measure of the load distribution capability of the sample. Stress-deformation relations of the unaged and three-week aged specimens are given as depending on the graphite due to see the effects of the graphite rate on the areas in Figure 6. While there is no significant difference between the unaged pure and graphite added samples, $20 \%$ graphite added mixture exhibits different performance compared to others after the three-week aging conditions. Since this test is performed at elastic region by considering the 6.5 deformations as target deformation, it enables to compare the flexibility properties of the samples in the linear viscoelastic region. In this
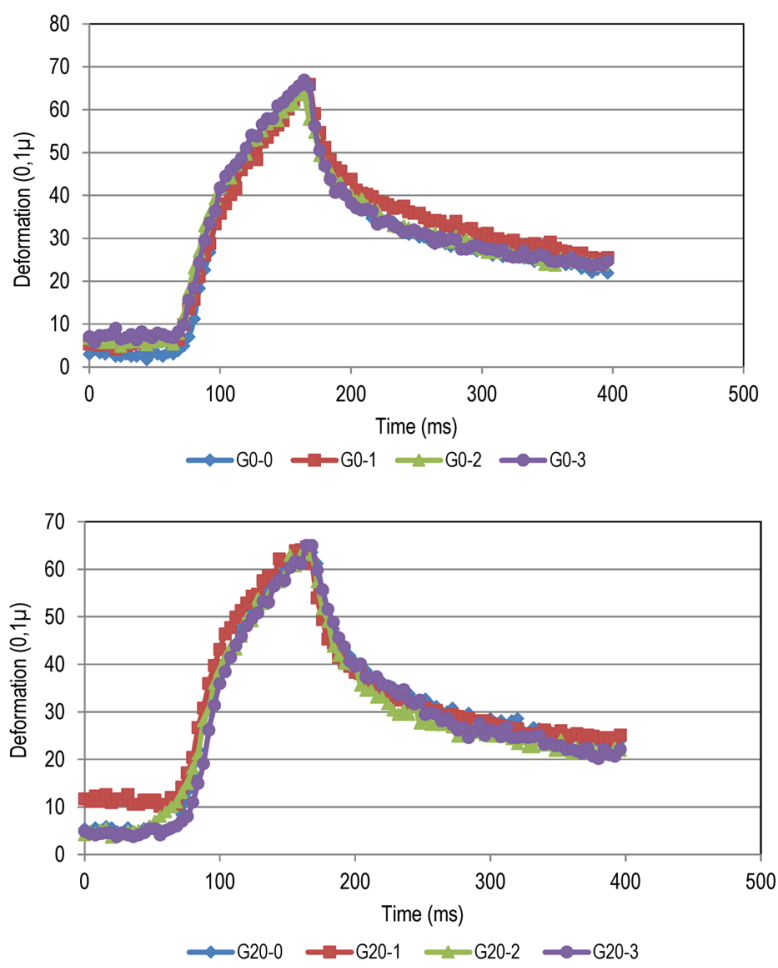

Fig. 5. The deformation-time relation of the asphalt mixtures respect, it can be concluded that the graphite added mixtures up to $15 \%$ graphite content do not have a significant performance compared to the pure mixture. Besides the high amount of graphite $(20 \%)$ take effect after 3-week aging conditions.

Figure 7 shows the effect of aging time on the stressdeformation relation of pure and G20 mixtures. It is seen that the areas under the curves change at a considerable degree depending on the aging period. In all samples, it was determined that the areas rise with the increase of the aging time indicating an improved ability to absorb the elastic energy, at medium temperatures.

Stiffness modulus $(\mathrm{Sm})$ of all mixtures types in all aging conditions are given in Figure 8. It is seen that graphite content does not have any influence on stiffness modulus at the unaged condition. Pure and $10 \%$ graphite added mixtures exhibit similar performance at all aging time. Sm values of these mixtures increase gradually with the aging time. However, the mixtures show different performance after $15 \%$ graphite content depending on the aging time. The aging time loses its significance for the $15 \%$ and $20 \%$ graphite added mixtures. The Sm values of the G15 and G20 mixtures after 1, 2 and 3 weeks are close to each other but $49-58 \%$ higher than that of the unaged ones. $20 \%$ graphite content also induces $44 \%$ increment in the Sm values of the pure mixture.

\subsection{Indirect tensile fatigue test results}

In the fatigue test, three samples experimented to each type of mixture. The load repetition number - deformation relations of the pure and $20 \%$ graphite-added speci-
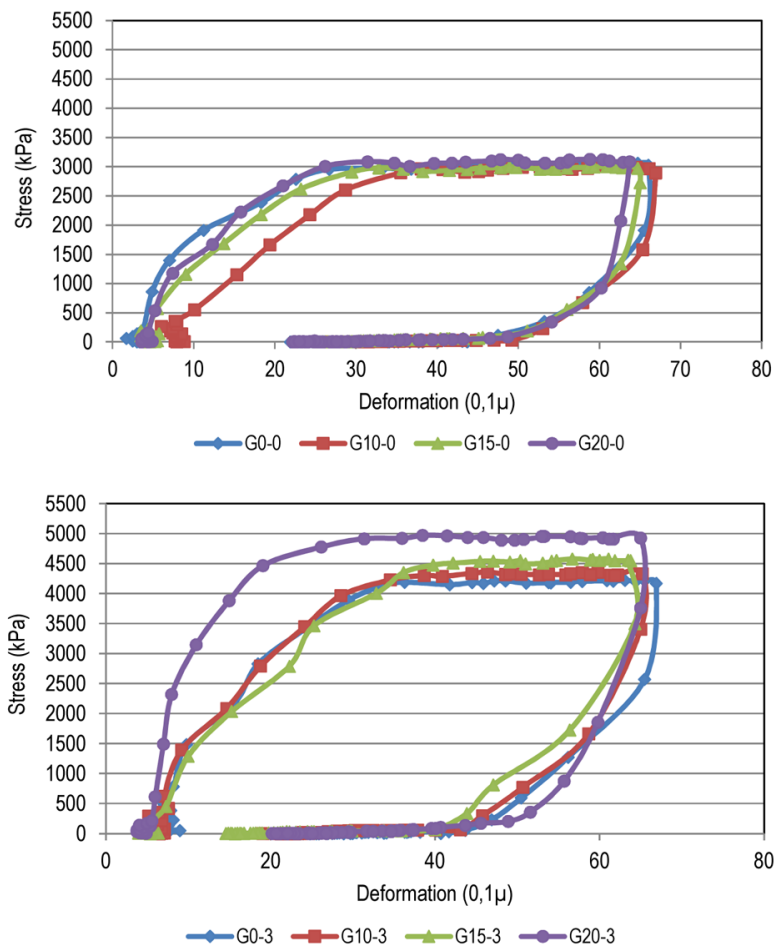

Fig. 6. The stress-deformation relation of the asphalt mixtures with graphite ratio 

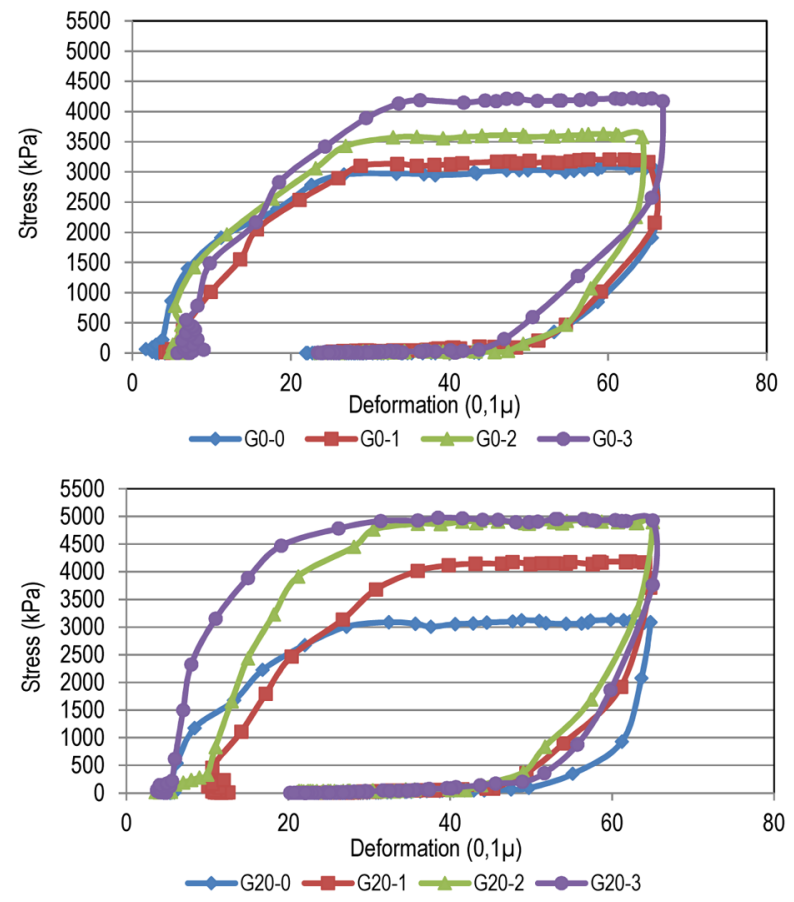

Fig. 7. The stress-deformation relation of the asphalt mixtures with aging

mens at different aging times are given in Figure 9. These curves belong to a nearest average of the three samples tested for each type of mixture. As it can be seen from the figures, all samples show a rapid deformation at the beginning and the increase of deformation trend continues linearly and then increases rapidly again. The rapid deformation increase of the curves at the beginning is caused by the decreasing of the air volume due to compression in the samples. The specimens exhibit elastic behavior for certain time by inducing a linear increase in deformations. After the initial crack in the specimen, the deformation increase accelerates again. In the phase after the beginning of the crack, which is called as the third region in the pure mixture, it is seen that the samples do not take up much load and break even before reaching the third region. In graphite-added samples, the third region is obviously formed. In other words, after the beginning

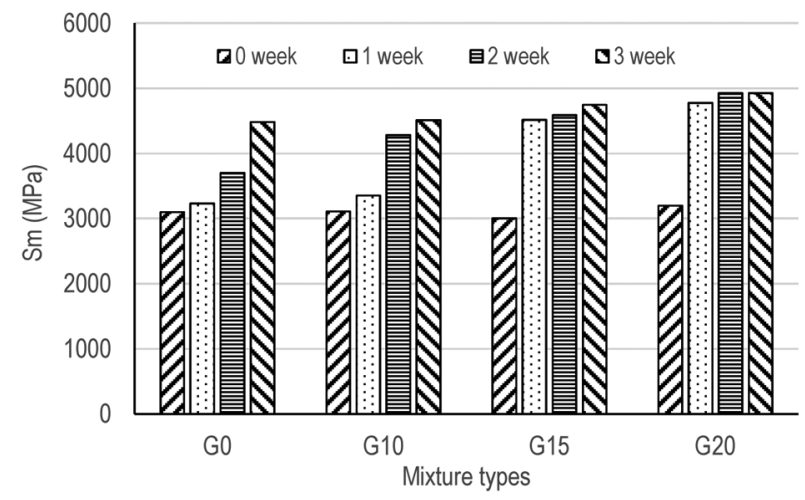

Fig. 8. The stiffness modulus (Sm) values of mixtures in aging conditions
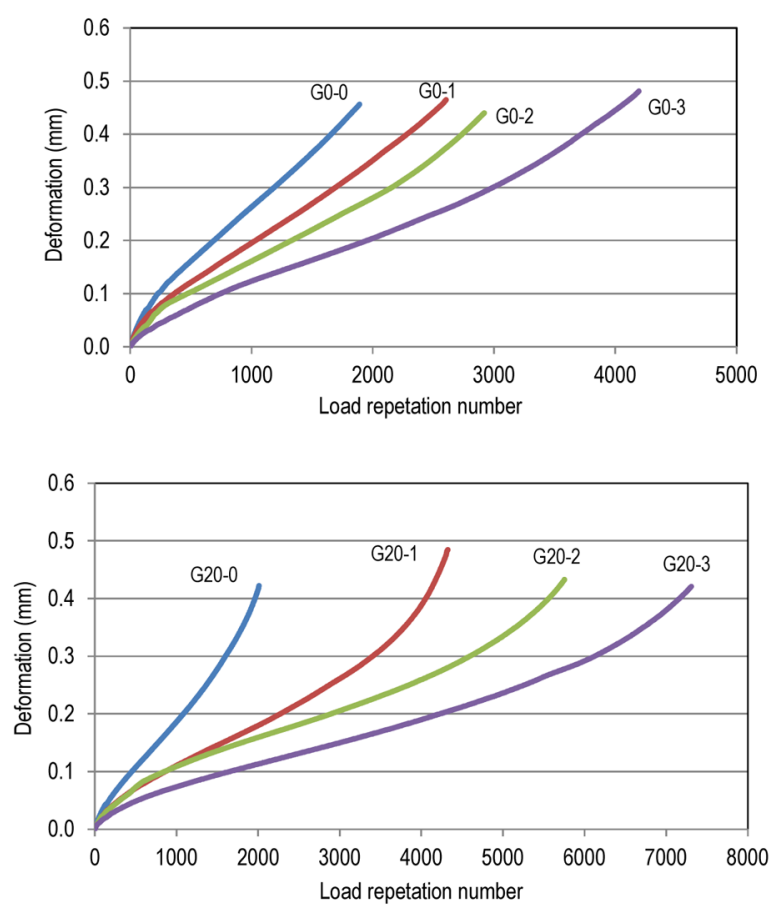

Fig. 9. The load repetition number-deformation relation of the mixtures with aging

of the crack, the graphite-added specimens show more resistance to the progress of the crack.

The load repetition number of all sample types increases significantly with the increase of aging time. Since the samples were collapsed at different deformation levels, $4 \mathrm{~mm}$ deformation was selected as the threshold value, which is the lowest deformation level reached by all samples in order to make a correct comparison between them. The average load repetition numbers of the specimens at $4 \mathrm{~mm}$ deformation are given Figure 10. The figure provides for assessing the aging effect on mixture by considering the slope of the curves. Pure and G10 mixtures have the lowest slope, G15 and G20 have the highest. Effects of aging time on load repetition number is more pronounced after the $15 \%$ graphite content. G10, G15 and G20 mixtures have 7\%, 65\% and 78\% higher load repetition number compared to the pure mixture after 3-week aging condition.

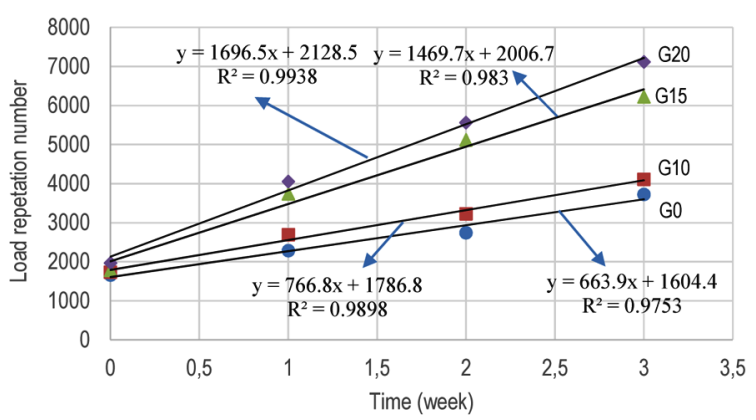

Fig. 10. The load repetition numbers of the mixtures at $4 \mathrm{~mm}$ deformation 

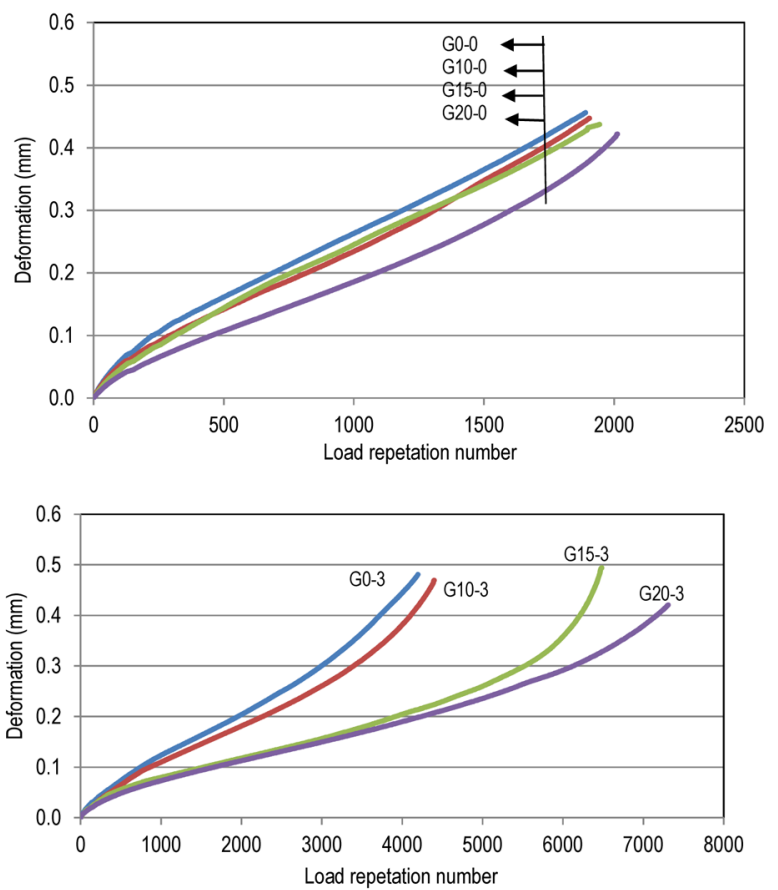

Fig. 11. The load repetition number-deformation relation of the mixtures

The deformation-load repetition number relationship of samples in the different graphite contents is given Figure 11 for the unaged and 3-week aged conditions. The graphite content in the unaged samples has no significant effect on the load repetition number but the increase of the graphite content with aging time has a significant effect on the load repetition number.

The variation of load repetition number versus graphite content for original and aged mixtures are given in Figure 12. Here, it can be said that graphite-added samples are more aged, in other words, they are more affected from aging. However, graphite-added mixtures which take more load repetition number than the pure mixture in the fatigue test will be resistant to repeated loads of traffic for a longer time without cracking at medium temperatures. The curves are become upright and become decumbent at the left and the right side of the $15 \%$ graphite content at the aged situations. Hence the $15 \%$ graphite content can be assumed as the most effective value in terms of fatigue life.

\section{Conclusions}

In this study, the effects of graphite on mechanical features of stone mastic asphalt pavement were researched. Mechanical tests such as Marshall stability and flow, indirect tensile stiffness modulus and indirect tensile fatigue tests were applied to bituminous mixtures at three different proportions of graphite by weight $10 \%, 15 \%$ and $20 \%$ of bitumen. It was determined that there is no significant difference in mechanic properties of graphite added mixtures compared to the pure mixture at the unaged condition. The aging time considerably effects the performance

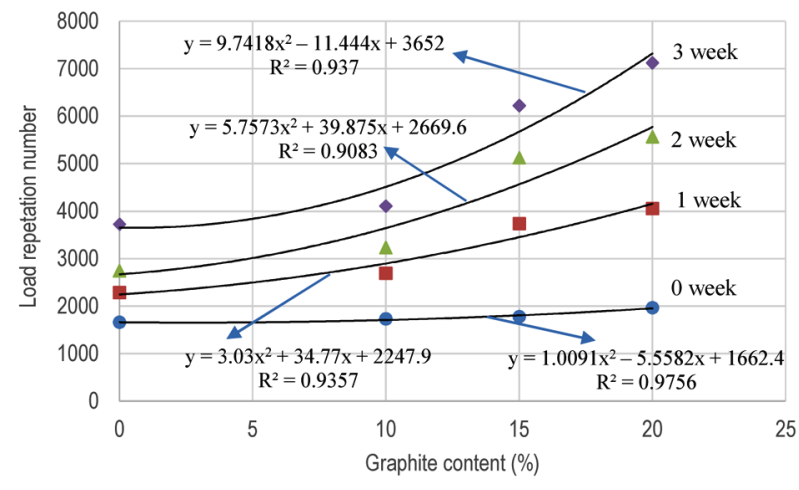

Fig. 12. The load repetition number-graphite ratio relation of the mixtures

of pure and graphite added mixtures. The area under the stress-deformation curves of aged mixtures indicates an improved ability to absorb the elastic energy, at medium temperatures. After $15 \%$ graphite content the aging time lose its significance in terms of stiffness modulus. The fatigue test results are also similar to the stiffness modulus' test results. While the load repetition number of all mixture closes each other, graphite added mixture exhibits a superior performance after aging. Effects of aging time on load repetition number are more pronounced after the $15 \%$ graphite content. G10, G15 and G20 mixtures have $7 \%, 65 \%$ and $78 \%$ higher load repetition number compared to the pure mixture after 3-week aging condition.

Finally, it was found, $15 \%$ graphite content is an effective ratio when considering the elastic response, the absorbed energy, the deformation behavior after the initial crack and load repletion number induced to deterioration. According to these results, graphite generally used for improving the thermal properties in literature were also determined to contribute to mechanical properties of mixtures at medium temperatures.

\section{Acknowledgements}

This research was supported by FUBAP (Firat University Scientific Research Projects Unit) under the project number MF 16.37 for which the authors are greatly thankful. The findings and evaluations of the results of this study are not the official views of FUBAP.

\section{References}

ASTM C 131 Standard Test Method for Resistance to Degradation of Small-Size Coarse Aggregate by Abrasion and Impact in the Los Angeles Machine. ASTM International, 2014. https://doi.org/10.1520/C0131_C0131M-14

ASTM C 88 Standard Test Method for Soundness of Aggregates by Use of Sodium Sulfate or Magnesium Sulfate. ASTM International, 2013. https://doi.org/10.1520/C0088

ASTM D 4791 Standard Test Method for Flat Particles, Elongated Particles, or Flat and Elongated Particles in Coarse Aggregate. ASTM International, 2010. https://doi.org/10.1520/D4791-10

ASTM C127 Standard Test Method for Relative Density (Specific Gravity) and Absorption of Coarse Aggregate. ASTM International, 2015. https://doi.org/10.1520/C0127-15 
ASTM C128 Standard Test Method for Relative Density (Specific Gravity) and Absorption of Fine Aggregate. ASTM International, 2015. https://doi.org/10.1520/C0128-15

ASTM D854 Standard Test Methods for Specific Gravity of Soil Solids by Water Pycnometer. ASTM International, 2014. https://doi.org/10.1520/D0854-14

Aghazadeh Dokandari, P.; Oner, J.; Topal, A.; Sengoz, B. 2014. A laboratory study of an organic warm mix asphalt additive on aging characteristics of bituminous mixtures, Pamukkale University Journal Engineering Science 20: 332-337. https://doi.org/10.5505/pajes.2014.02411

Austroads Technical Report. 2002. Stone mastic asphalt surfacing. AAP asphalt guide.

Bražiūnas, J.; Sivilevičius, H.; Virbickas, R. 2013. Dependence of SMA mixture and its bituminous binder properties on bitumen batching system, mixing time and temperature on asphalt mixing plant, Journal of Civil Engineering and Management 19(6): 862-872. https://doi.org/10.3846/13923730.2013.843587

BS DD 213:1993 Method for determination of the indirect tensile stiffness modulus of bituminous mixtures. BSI Group, 1993.

Chen, J.; Wang, H.; Li, M.; Li, L. 2016. Evaluation of pavement responses and performance with thermally modified asphalt mixture, Materials and Design 111: 88-97. https://doi.org/10.1016/j.matdes.2016.08.085

Dong, Y.; Tan, Y. 2011. Mix design and performance of crumb rubber modified asphalt SMA, in GeoHunan International Conference 2011, 9-11 June 2011, Hunan, China. https://doi.org/10.1061/47623(402)10

Du, Y.; Wang, S. 2015. Oriented heat release in asphalt pavement induced by high-thermal-conductivity rods, Applied Thermal Engineering 90: 424-431. https://doi.org/10.1016/j.applthermaleng.2015.07.026

Francken, L. 1998. Bituminous binders and mixes. Rilem Reports. London and New York: E \& FN Spon.

Kim, Y.; Lim, J.; Lee, M.; Kwon, S.; Hwang, S.; Lee, J. 2015. Comprehensive evaluation of warm SMA using waxbased WMA additive in Korea, Journal of Testing and Evaluation 43(5): 1230-1238. https://doi.org/10.1520/JTE20130144

Kok, B. V.; Yilmaz, M.; Akpolat, M. 2014. The effect of SBS and wax modification on stability and stiffness of stone mastic asphalt, Turkish Journal Science Technology 9: 56-72.

Liu, X.; Liu, W.; Wu, S.; Wang, C. 2014. Effect of carbon fillers on electrical and road properties of conductive asphalt materials, Construction and Building Materials 68: 301-306. https://doi.org/10.1016/j.conbuildmat.2014.06.059

Liu, Y.; Han, S.; Zhang, Z. 2012. Design and evaluation of gapgraded asphalt rubber mixtures, Materials and Design 35: 873-877. https://doi.org/10.1016/j.matdes.2011.08.047

Lu, L.; Ao, Z.; He, Y.; Ding, Q.; Hu, S. 2008. Experimental study on conductive asphalt concrete using steel slag as aggregate, in the $1^{\text {st }}$ International Conference on Microstructure Related Durability of Cementitious Composites, 2008, Nanjing, China, 1043-1050.
Mamlouk, M.; Witczak, M.; Kaloush, K.; Hasan, N. 2005. Determination of thermal properties of asphalt mixtures, Journal of Testing and Evaluation 33(2): 118-126. https://doi.org/10.1520/JTE12592

Moghaddam, T. B.; Karim, M. R.; Syammaun, T. 2012. Dynamic properties of stone mastic asphalt mixtures containing waste plastic bottles, Construction and Building Materials 34: 236-242. https://doi.org/10.1016/j.conbuildmat.2012.02.054

Mokhtari, A.; Nejad, F. M. 2012. Mechanistic approach for fiber and polymer modified SMA mixtures, Construction and Building Materials 36: 381-390. https://doi.org/10.1016/j.conbuildmat.2012.05.032

Pan, P.; Wu, S.; Xiao, Y.; Wang, P.; Liu, X. 2014. Influence of graphite on thermal properties and anti-aging properties of asphalt binder, Construction and Building Materials 68: 220-226. https://doi.org/10.1016/j.conbuildmat.2014.06.069

Radziszewski, P. 2007. Modified asphalt mixtures resistance to permanent deformations, Journal of Civil Engineering and Management 13(4): 307-315.

Reed, J. 2010. Evaluation of the effects of aging on asphalt rubber pavements: MSC thesis. Arizona State University.

Shatnawi, S. 2012. Superior aging characteristics of asphalt rubber, in Asphalt Rubber Conference, 2012, 1-27.

Tongyan, P.; Yang, L.; Zhaoyang, W. 2012. Development of an atomistic-based chemophysical environment for modeling asphalt oxidation, Polymer Degradation and Stability 97: 2331-2339. https://doi.org/10.1016/j.polymdegradstab.2012.07.032

TS EN 12697-34 Bituminous mixtures - Test methods for hot mix asphalt - Part 34: Marshall. Turkish Standards Institution, 2004.

Xiao, F.; Amirkhanian, A. N.; Amirkhanian, S. N. 2011. Longterm aging influence on rheological characteristics of asphalt binders containing carbon nanoparticles, International Journal of Pavement Engineering 12(6): 533-541. https://doi.org/10.1080/10298436.2011.560267

Van Bijsterveld, W.; Houben, L. J.; Scarpas, A.; Molenear, A. A. 2001. Using pavement as solar collector: effect on pavement temperature and structural response, Transportation Research Record: Journal of the Transportation Research Board 1778: 140-148. https://doi.org/10.3141/1778-17

Wang, Y.; Sun, L.; Qin, Y. 2015. Aging mechanism of SBS modified asphalt based on chemical reaction kinetics, Construction and Building Materials 91: 47-56. https://doi.org/10.1016/j.conbuildmat.2015.05.014

Yao, H.; Dai, Q.; You, Z.; Ye, M.; Yap, Y. K. 2016. Rheological properties, low-temperature cracking resistance, and optical performance of exfoliated graphite nanoplatelets modified asphalt binder, Construction and Building Materials 113: 988-996. https://doi.org/10.1016/j.conbuildmat.2016.03.152

Zoorob, S. E.; Suparma, L. B. 2000. Laboratory design and investigation of properties of continuously graded Asphaltic concrete containing recycled plastics aggregate replacement (Plastiphalt), Cement and Concrete Composites 22(4): 233-242. https://doi.org/10.1016/S0958-9465(00)00026-3

Baha Vural KÖK. Was born in Tukey in 1978. He is an associate professor in civil engineering at Firat University where he teaches highways design, bituminous materials, flexible asphalt pavements, earthworks and other courses. His research interests include bitumen modification, asphalt mixture design, performance of asphalt pavement. He currently works on economic asphalt pavements using waste materials. He has a lot of published manuscript at reputable journals.

Mehmet YILMAZ. Was born in Tukey in 1981. He is an associate professor in civil engineering at Firat University where he teaches highways design, experiments on bituminous materials, earthworks and other courses. His work focuses on bitumen modification, asphalt mixture design, performance of asphalt pavement. He currently works on self-treated asphalt pavements. He has a lot of published manuscript at reputable journals.

Yunus ERKUS. Was born in Turkey in 1989. He is a PhD student and an assistant professor at Firat University. He is a civil engineer. His research interests focus on asphalt pavements. 